\title{
Effect of Implementation of Teaching Modules about Physiological and Psychological Parameters on Expected Clinical Outcomes of Patients with Chronic Obstructive Pulmonary Disease
}

\author{
Soheir Mohamed Wehieda ${ }^{1}$, Amal Amin El-Sheikh², Salwa Abd El Gawad Sallam² \\ ${ }^{1}$ Medical Surgical Nursing Department, Faculty of Nursing, Alexandria University, Alexandria, Egypt \\ ${ }^{2}$ Medical Surgical Nursing Department, Faculty of Nursing, Menoufia University, Shebin El-Kom, Egypt
}

Email address:

amal.elshikh@hotmail.com (A. A. El-Sheikh), salwa_sallam@yahoo.com (S. A. El G. Sallam)

To cite this article:

Soheir Mohamed Wehieda, Amal Amin El-Sheikh, Salwa Abd El Gawad Sallam. Effect of Implementation of Teaching Modules about Physiological and Psychological Parameters on Expected Clinical Outcomes of Patients with Chronic Obstructive Pulmonary Disease. American Journal of Nursing Science. Vol. 6, No. 5, 2017, pp. 370-381. doi: 10.11648/j.ajns.20170605.11

Received: July 19, 2017; Accepted: August 2, 2017; Published: September 8, 2017

\begin{abstract}
Dyspnea and fatigue, the two most common symptoms experienced by patients with chronic obstructive pulmonary disease, are believed to result in decreased activity levels and poor quality of life. This study was carried out to determine effect of implementation of teaching modules about physiological and psychological parameters on expected clinical outcomes of patients with chronic obstructive pulmonary disease. A quasi experimental research design was utilized to achieve the aim of this study. This study was conducted at chest department of Menofia University Hospital. A purposive sample of 140 adult patients, three tools was used for data collection. Bio socio demographic assessment questionnaire, physiological measurement tool and anxiety scale. There were highly statistical significant differences between study and control groups post one and two months of teaching regarding dyspnea, fatigue, cough vital signs and anxiety. Also it was found that there was a positive correlation between dyspnea, fatigue and anxiety. A teaching carried out for the patients of the study group had positive effect on dyspnea, fatigue, cough, vital signs and anxiety and there was a positive correlation between dyspnea, fatigue and anxiety. Initiate outpatient hospital based pulmonary rehabilitation program. A booklet should be available and distributed for all patients with choronic obstructive pulmonary disease.
\end{abstract}

Keywords: Teaching Modules, Physiological and Psychological Parameters, Clinical Outcomes, Chronic Obstructive Pulmonary Disease

\section{Introduction}

Chronic obstructive pulmonary disease (COPD) is a preventable and treatable disease. Its pulmonary component is characterized by airflow constraint that is not fully reversible. The airflow constraint is usually progressive and associated with an inflammatory response of the lung to noxious particles or gases [1]. There are 210 million COPD patients in the world. In the United States COPD the 4th cause of death and according to the World Health Organization (WHO), for 2030, COPD will shift to 3rd cause for death in the world [2].

Approximately $90 \%$ of COPD deaths arise in low and middle income countries, because effective strategies for prevention and control are not implemented [3]. The incidence of COPD in Middle East and North Africa was lower than that reported in industrialized countries. Under reporting and risk factors other than smoking may contribute to this difference [4].

According to Statistics by Country for COPD, (2013) the extrapolation of undiagnosed occurrence rate of COPD in Egypt is 4,197,651 and the diagnosed occurrence rate in Egypt is $3,777,886$ [5]. It was anticipated that 80 million people worldwide have moderate to severe COPD. COPD are responsible for extensive healthcare utilization, with physician follow up and hospitalization [6]. 
Risk factors for COPD include environmental exposures and host factors. The environmental risk factor for COPD is cigarette smoking, other types of tobacco, Passive smoking, prolonged and intense exposure to occupational dusts and chemicals, indoor air pollution, and outdoor air pollution. Also risk factor for COPD involves a gene environment interaction $[1,7]$.

Dyspnea and fatigue are the two significant symptoms of COPD patients [8]. Any patient who feels exhausted for more than 1 month is considered as affected by chronic fatigue [9]. Chronic fatigue is the most common sensation in patients with COPD that interferes with the quality of life but almost ignored $[10,11]$. COPD patients had hard breathing followed by dyspnea which leads to inability to perform daily activities the patient gets out of breath and is affected with early fatigue [12].

Co morbid psychological impairments as anxiety and depression are common in COPD and are often associated with increased disability and morbidity [13, 14]. Jain and Lolak (2009) [15] stated that anxiety and depression the most common and least treated co morbidities of COPD.

The impact of depression and anxiety in COPD is substantial. Depression and anxiety are extensively associated with decreased the level of activity and worse health status [16]. Untreated or incompletely treated depression and anxiety may affect the compliance with medical treatment, increased frequency of hospital admissions and length of stay, increased consultations with primary care physicians, increasing medical costs, poor quality of life and death. Impairments in physical functioning, vital, and general health appear to be related to disease severity, whereas difficulties in social and emotional functioning appear to be related to co morbid medical conditions [17]. Emery, et al., (2008), [18] stated that psychological distress in patients with COPD is associated with impaired quality of life and consequently, diminish the patient's role within the family and the community restricted activities of daily living, low self-esteem, somatization, and attitudes toward treatment [19-21].

There is no cure for COPD, thus treatment focuses on managing the disease and control the symptoms [22]. Pulmonary Rehabilitation programs are the treatment that leads to improve symptom and increase activity [23]. Pulmonary rehabilitation uses a different method combining education and exercise in order to improve the activity levels, symptoms and the patients complains. Evidence has shown that, to this day, pulmonary rehabilitation has led to a reduction in complaints mainly of dyspnea and fatigue and an increased tolerability to activities [8, 24]. Also Kozora, et al., (2002) [25] found decreased anxiety among patients with COPD participating in a pulmonary rehabilitation program which include exercise, education and stress reduction compared with a group receiving education and stress reduction alone.

Respiratory exercises such as lip pursing or diaphragm respiration are considered as a part of pulmonary rehabilitation programs, which could lead to an improvement in gas exchange, exercise tolerance and quality of life. The goal of respiratory exercises in patients with COPD is for the patients to replace their ineffective respiratory techniques with effective ones and to discharge secretions from the lungs through deep respiratory exercises and effective coughing [26].

Since the changes due to a chronic disease affect the patient's quality of life, it is very important that the medical staff pay special attention to such disease. Nurses, who take care of the individuals suffering from chronic diseases, must considered patient quality of life by applying pulmonary rehabilitation program [27]. Nurses play a key role in identifying potential candidates for pulmonary rehabilitation and in facilitating and reinforcing the material learned in the rehabilitation program. Patient education is a major component of pulmonary rehabilitation [23].

Providing information and education is foundational to enhance the patient and family's ability to cope. Patient's education is a critical component of COPD management and fundamental to increase a patient's ability to self-manage the disease. Educational interventions that increase knowledge alone are insufficient; patients must also integrate the knowledge and tools they learn into their daily lives, and this must lead to behavior modification. Education offered in their preferred learning style is more likely to lead to successful learning and increases learner satisfaction [23].

Therefore the researcher decided to perform a study to determine effect of implementation of teaching modules about physiological and psychological parameters on expected clinical outcomes of patients with chronic obstructive pulmonary disease.

Operational definitions:

Physiologic parameters are measured by dyspnea, fatigue, cough, and vital signs.

Psychological parameter are measured by anxiety

Patient education include: breathing exercises, bronchial hygiene, inspiratory muscle training and progressive muscle relaxation technique

\section{Subjects and Methods}

\subsection{Aim of the Study}

The aim of this study is to determine effect of implementation of teaching modules about physiological and psychological parameters on expected clinical outcomes of patients with chronic obstructive pulmonary disease.

\subsection{Study Hypotheses}

a. The study group subjects who exposed to the teaching modules exhibit a lower level of dyspnea as compared to their control who do not exposed.

b. The study group subjects who exposed to the teaching modules exhibit a lower level of fatigue as compared to their control who do not exposed.

c. The study group subjects who exposed to the teaching modules exhibit a lower level of anxiety as compared to their control who do not exposed. 


\subsection{Study Design}

A quasi experimental research design was utilized to achieve the aim of this study.

\subsection{Setting}

The study was conducted at chest department at Menofia University Hospital.

\subsection{Subjects}

A purposive sample of 140 adult patients who were admitted to the chest department and was recruited in this study based on the following:

\subsubsection{Power Analysis}

The total number of patients to be selected was estimated using the following equation: $n=\left(z^{2} \times p \times q\right) / D^{2}$. Since the actual prevalence of COPD was $10 \%$, and a value of 0.025 was chosen as the acceptable limit of precision (D). Based on these assumptions, the sample size was estimated to be 140 patients. They were selected randomly and were divided alternatively into two equal groups, 70 patients in each group.

Group (I): study group were exposed to a teaching modules, patient education include: breathing exercises, bronchial hygiene, inspiratory muscle training and progressive muscle relaxation technique along with routine hospital care.

Group (II): control group were exposed only to routine hospital care.

The patients had been selected according to the following criteria:

\subsubsection{Inclusions Criteria Included}

a. Adult patients with a diagnosis of COPD in the mild or moderate stage.

b. Free from any other chronic diseases such as malignancy, liver or renal impairment, diabetes mellitus, or heart failure.

c. Not receiving treatment for depression or anxiety

\subsection{Tools: Three Tools Were Utilized for Data Collection}

\subsubsection{Tool I Bio Socio Demographic Assessment Questionnaire}

This tool was developed by the researcher based on the review of the relevant literature [28]. It was used to determine the bio socio demographic data of patients. It was constricted of the following parts:

Part 1: Patient's sociodemographic: such as age, sex, level of education, occupation, and marital status.

Part two: Clinical data such as: smoking habits, assessment of cough whether it was dry or moist in order to ensure the respiratory condition of the patient.

\subsubsection{Tool II Physiological Measurement Tool}

This tool was developed based on the reviewing of the relevant literature [29] to identify patients' physiological problems and its extent. It was included of 3 parts:

Part 1

(i) Dyspnea severity measurement: a measuring scale to determine the severity of dyspnea, and it consists of items as short of breath, hard to breath, feel like I need air, shallow breathing, and gasping breath. This scale was adopted from kinsman, et al., (1983) [30] and was translated into Arabic by the researcher and then the patient was asked to rate the sensation of dyspnea from 0 to 4 over the past week. Where $0=$ not at all, $1=$ a little, $2=$ moderately, $3=$ quite a bit, $4=$ extremely.

Part 2

(ii) Vital signs assessment: It was used to assess the vital signs

Part 3

(iii) Fatigue was measured using Functional Assessment of Chronic Illness Therapy (FACIT) Fatigue Scale (Version 4 ), this scale has been developed and reviewed by Webster, et al., (2003) [31] and was tested for reliability by test-retest reliability (ICC $=0.95$ ) by Chandran, et al., (2007) [32] The FACIT Fatigue Scale is a short, 13-item, easy to administer tool that measures an individual's level of fatigue during their usual daily activities over the past week. Scoring: Items are scored as follows: $4=$ not at all; $3=$ a little bit; $2=$ somewhat; $1=$ quite a bit; $0=$ very much, except items \#7 and \#8 which are reversed scored. Score range 0-52. A score of less than 30 indicates severe fatigue.

\subsubsection{Tool III the Anxiety Scale}

This scale has been developed and reviewed by Spellberger, et al., (1983) [33] and was translated, and tested for reliability (coefficient alpha of 0.92) by Abd-Elkahlek (2008) [34]. The scale measures two dimensions of anxiety, first: Anxiety as state and second: as a trait. Each dimension consists of 20 items regarding present feeling in a likert format ranging from (1) strongly agree to (4) strongly disagree. The total score value ranges between $20-80$. Higher scores mean higher level of anxiety. The researcher uses the dimension anxiety as state.

\subsection{Methods}

1. An official permission was obtained by the researcher from the hospital administrator and the head of chest unit.

2. Tools I and II were developed by the researcher and was tested for content validity by three experts in the field of Medical Surgical Nursing, Faculty of Nursing, Menofia University, and two experts in the field of Medicine, Faculty of Medicine, Menofia University, modifications were done accordingly.

3. Reliability: A test retest method was used to test reliability of tool I and II. The comparison is expressed through correlation coefficient alpha for tool I it was 0.93 and for tools II except part 3 (visual analogue scale of fatigue) it was 0.942 .

4. Pilot study: a pilot study was conducted on 10 patients to evaluate the tentatively developed tool for clarity, 
feasibility and applicability accordingly the necessary adjustments were carried out. Data obtained from the pilot was excluded from the study.

5. Ethical consideration: at the initial interview each patient was informed about the purpose and benefits of the study, and informed that their participation is voluntary, also confidentiality, privacy and anonymity of the patients were assured. finally, patients' formal consent for participations has been obtained.

\subsubsection{Data Collection}

a. Data collection was extended from October 2014 to June 2015. The data were collected using the interview and continuous observation methods

b. Each patient who agreed to participate in the study and fulfilling the inclusion criteria has been interviewed individually by the researcher in the chest department.

c. A purposive sample was divided randomly and alternatively into two equal groups, 70 patients in each group.

Study group (1): were exposed to teaching modules, patient education includes: breathing exercises, bronchial hygiene, and inspiratory muscle training and progressive muscle relaxation technique along with routine hospital care.

Control group (11): were exposed to routine hospital care

a. Data collection was passed by 4 phases as the following

\subsubsection{Assessment Phase}

b. On admission for every patient: the patient's sociodemographic and clinical data was filled by the researcher using tool I, physiological parameters and anxiety state was measured using tool II and tool III

\subsubsection{Planning Phase}

The researcher went through extensive literature review [1, $7,8,16,25,27]$ to prepare the teaching module for patients with COPD disease of the study group based on needs identified in assessment phase, goals, priority of care and expected outcomes were formulated and taking first in consideration. An illustrative structured colored booklet was prepared to be introduced to study group as a guide for all pertinent data related to teaching module. The booklet was written in simple Arabic language supported by illustrative pictures as a guide for illiterate patients. The booklet was tested by the experts in the medical surgical nursing field to check the content relevance, clarity and feasibility.

\subsubsection{Implementation Phase}

a. Patients in the control group received only routine hospital care.

b. Patients of the study group received a teaching for 6 weeks.

The teaching was given for each patient individually and explained through modified lectures, discussions, demonstration and re-demonstration based on his or her needs and level of understanding. An instructional media was used. Each session took approximately 30-45 minutes, 3 times per week at morning shift in the chest department.
Teaching was done in 8 sessions, two sessions for health education, one session about breathing exercise, one session about inspiratory muscle training, one session about progressive muscle relaxation technique, two session for practical part as through demonstration and re-demonstration under researcher supervision and from session 8 patient carry the procedure alone.

The researchers telephone number were given to studied patients while patients' telephone number were taken to contact them and ensure that they carry the procedure and health education and meeting them during follow up visits in outpatients clinics to complete data collection during follow up period.

The teaching included

A. Theoretical part

All patients of the study group received health education about relevant topics associated with COPD e.g., anatomy, pathophysiology, medications, smoking cessation, symptom management, daily exercise, anxiety management, relaxation, etc. Patient education aims to equip the patient with the knowledge and skills they need to manage their disease. Also the researcher provides each participants of the study group a written booklet.

B. Practical part

i. Breathing Exercise

1. The patient was asked to lie on back on a flat surface or in bed, with knees bent and head supported. A pillow placed under patient's knees to support legs. Ask the patient to place one hand on upper chest and the other just below rib cage. This will allow feeling diaphragm move as patients breathe.

2. Patients were asked to breathe in slowly through nose so that stomach moves out against hand. The hand on chest should remain as still as possible.

3. Tighten stomach muscles, letting them fall inward as patients exhale through pursed lip. Patient was asked to put the hand on upper chest and must remain as still as possible.

Patients were instructed that this exercise should be carried 3-4 times per day each for 10 minutes, and he/she was asked to gradually increase the amount of time spend doing this exercise.

ii. Inspiratory muscle training

Each patient was asked to seal his mouth around the mouthpiece and inhale deeply until the first ball rose into the first column during the first week, and raise the second ball into the second column during the second week, and raise the third ball into the third column during the third week.

Every patient was asked to sustain the ball raised in its column for 3-10 second according his tolerance.

iii. Progressive muscle relaxation technique

Each patient was asked to tense each muscle group for 5 to 7 second and then relaxed for 20 to 30 second: a systemic approach was followed until the patient tensed and relaxed all muscle groups in his body

The muscles in the body were divided into six groups, the first groups was the muscle of the head and neck, the second 
was the two arms muscle, the third was the muscle of the abdomen, the fourth was the muscles of the back, the fifth was the muscles of the right leg, and finally the last group was the muscles of the left leg.

The patient practiced the inspiratory muscle training using the flow incentive spirometer for 10-15 min first, and then the progressive muscle relaxation technique for 10-15 min. These techniques were repeated three times per day for 6 weeks.

\subsubsection{Evaluation Phase}

1. Participants of both groups were assessed immediately on hospital admission using tool I for collecting the demographic and clinical data. Also the physiological parameters and anxiety state was measured using tool II and tool III on admission as a baseline for both groups.

2. Assessment of the physiological parameters and anxiety state were measured using tool II and tool III after one and two months post intervention.

\subsubsection{Statistical Analysis}

Data were collected, tabulated, statistically analyzed using an IBM personal computer with Statistical Package of Social Science (SPSS) version 20 where the following statistics were applied.

a. Descriptive statistics: in which quantitative data were presented in the form of mean $(\bar{X})$, standard deviation (SD) and qualitative data were presented in the form numbers (No) and percentages (\%).

b. Analytical statistics: The used tests of significance included:
1. Chi-square test $\left(\chi^{2}\right)$ was used to study association between qualitative variables.

2. Student t-test: is a test of significance used for comparison between two groups having quantitative variables

3. Mann-Whitney test (nonparametric test): is a test of significance used for comparison between two groups not normally distributed having quantitative variables.

4. Paired t-test: is a test of significance used for comparison between two related groups having quantitative variables.

5. McNemar's test: assess the significance of the difference between two correlated proportions, such as might be found in the case where the two proportions are based on the same sample of subjects or on matched-pair samples.

6. Wilcoxon signed rank test (nonparametric test): is a test of significance used for comparison between two related groups not normally distributed having quantitative variables

7. Pearson correlation ( $r$ ): is a test used to measure the association between two quantitative variables.

8. $\mathrm{P}$ value of $>0.05$ was considered statistically nonsignificant

9. $P$ value of $<0.05$ was considered statistically significant

10. $\mathrm{P}$ value of $<0.001$ was considered statistically highly significant [35].

\section{Results}

Table 1. Distributions of patients of the both groups according to their socio-demographic data.

\begin{tabular}{|c|c|c|c|c|c|}
\hline \multirow{2}{*}{ Socio demographic Characteristics } & \multicolumn{2}{|c|}{ Study group $\mathrm{No}=70$} & \multicolumn{2}{|c|}{ Control group $\mathrm{No}=70$} & \multirow{2}{*}{$\chi^{2}$ p value } \\
\hline & No. & $\%$ & No. & $\%$ & \\
\hline Age / years $(\bar{X} \pm \mathrm{SD})$ & $51.8 \pm 12.8$ & & $52.2 \pm 12.6$ & & $0.156 * 0.874(\mathrm{NS})$ \\
\hline \multicolumn{6}{|l|}{ Gender } \\
\hline Female & 27 & 38.6 & 26 & 37.1 & 0.03 \\
\hline Male & 43 & 61.4 & 44 & 62.9 & $0.861(\mathrm{NS})$ \\
\hline \multicolumn{6}{|l|}{ Residence } \\
\hline Urban & 14 & 20 & 20 & 28.6 & 1.40 \\
\hline Rural & 56 & 80 & 50 & 71.4 & $0.236(\mathrm{NS})$ \\
\hline \multicolumn{6}{|l|}{ Level of education } \\
\hline Illiterate & 57 & 81.4 & 50 & 71.4 & \\
\hline Secondary education & 3 & 4.3 & 4 & 5.7 & 3.31 \\
\hline Higher education & 10 & 14.3 & 16 & 22.8 & $0.507(\mathrm{NS})$ \\
\hline \multicolumn{6}{|l|}{ Marital state } \\
\hline Single & 13 & 18.6 & 9 & 12.8 & 1.28 \\
\hline Married & 55 & 78.6 & 60 & 85.7 & $0.527(\mathrm{NS})$ \\
\hline Widow & 2 & 2.9 & 1 & 1.4 & \\
\hline \multicolumn{6}{|l|}{ Occupation } \\
\hline House wife & 22 & 31.4 & 26 & 37.1 & \\
\hline Farmer & 39 & 55.7 & 30 & 42.9 & 5.01 \\
\hline Employee & 7 & 10.0 & 7 & 10 & $0.171(\mathrm{NS})$ \\
\hline Shoe maker & 2 & 2.9 & 7 & 10 & \\
\hline
\end{tabular}

*t-test NS: non-significant

Table 1, showed that there were no statistical significant differences between control and study groups regarding socio demographic data. The mean age for the study and control group was $51.8 \pm 12.8$ and $52.2 \pm 12.6$ years respectively.
$61.4 \%$ of study group and $62.9 \%$ of the control group were male. More than two thirds $(78.6 \%, 85.7 \%)$ of the study and control group respectively were married. In relation to educational level, more than two thirds of study and control 
group were illiterate $(81.4 \%$ and $71.4 \%$ respectively). Regarding occupation, about half of them were farmer.

Table 2. Distribution of patients of both studied group according to their smoking habits at two different intervals: on admission, and two months post intervention. $(N=140)$.

\begin{tabular}{|c|c|c|c|c|c|}
\hline \multirow{2}{*}{ Studied variable } & \multicolumn{2}{|c|}{ Study group $(\mathrm{N}=70)$} & \multicolumn{2}{|c|}{ Control group(N=70) } & \multirow{2}{*}{$\chi^{2}$ p value } \\
\hline & No & $\%$ & No & $\%$ & \\
\hline \multicolumn{6}{|c|}{ Smoking on admission } \\
\hline Yes & 49 & 70 & 47 & 67.1 & 0.13 \\
\hline No & 21 & 30 & 23 & 32.9 & 0.715 (NS) \\
\hline \multicolumn{6}{|c|}{ Number of packs / day on admission } \\
\hline One pack & 29 & 59.2 & 25 & 53.2 & 0.35 \\
\hline More than one & 20 & 40.8 & 22 & 46.8 & $0.551(\mathrm{NS})$ \\
\hline \multicolumn{6}{|c|}{ Smoking two month post teaching } \\
\hline Smoker & 10 & 20.4 & 27 & 57.4 & 13.8 \\
\hline Quitter & 39 & 79.6 & 20 & 42.6 & $0.001(\mathrm{HS})$ \\
\hline
\end{tabular}

NS: non-significant S: significant

Table 2, this table illustrates smoking habits among studied group. There was no statistically significant difference between study and control group regarding smoking and number of packs per day ( $\mathrm{P}>0.05 \%$ ) on admission. While there was a highly statistically significant difference between study and control group regarding condition of smoking two months post teaching $(\mathrm{P}<0.001)$. $79.6 \%$ of study group quit smoking.

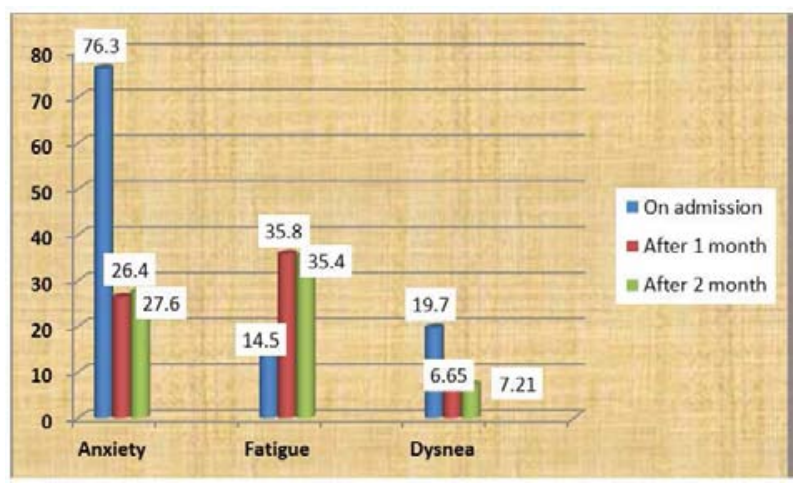

Figure 1. Distribution of patients of the study group according to mean anxiety, fatigue and dyspnea at three different intervals: on admission, one and two months post teaching.

This figure shows the mean anxiety in the study group on admission were $76.3 \pm 7.83$, which improves post one and two month to be $26.4 \pm 12.3,27.6 \pm 13.4$ respectively. In relation to fatigue the figure cleared that the fatigue in the study group on admission were $14.5 \pm 14.9$, which improves post one and two month to be $35.8 \pm 6.78,35.4 \pm 4.56$ respectively.
Regarding to dyspnea the figure shows that dyspnea in the study group on admission were $19.7 \pm 1.80$, which improves post one and two month to be $6.65 \pm 3.17,7.21 \pm 1.05$ respectively. There were highly statistical significant difference among study group regarding anxiety, fatigue and dyspnea between admission and one and two months post teaching $(\mathrm{P}<0.001)$.

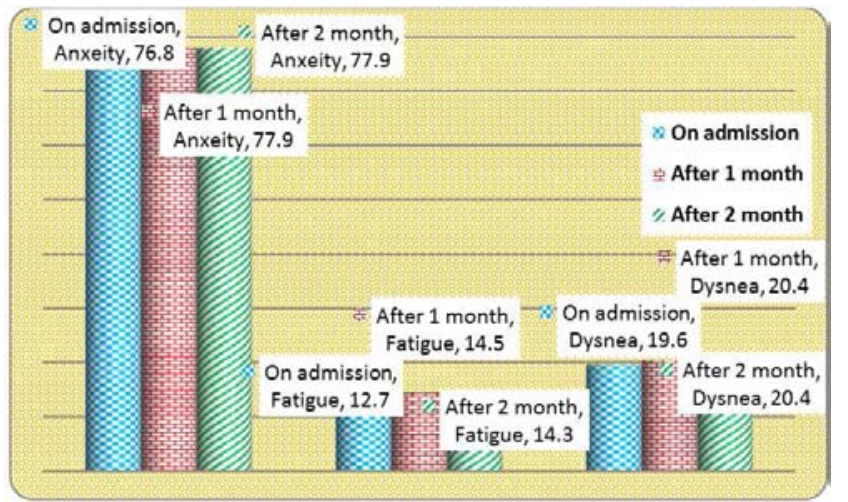

Figure 2. Distribution of patients of the control group according to mean anxiety, fatigue and dyspnea at three different intervals: on admission, one and two months post teaching.

This figure shows the distribution of mean anxiety, fatigue and dyspnea among control group. There was no statistical significant difference in the control group regarding anxiety, fatigue and dyspnea symptoms between admission and one and two month post teaching.

Table 3. Distribution of patients of both study and control group according to mean anxiety, fatigue and dyspnea at three different intervals: on admission, one and two months post teaching.

\begin{tabular}{|c|c|c|c|c|c|c|c|c|c|}
\hline \multirow{3}{*}{$\begin{array}{l}\text { Studied } \\
\text { variable }\end{array}$} & \multicolumn{2}{|c|}{ On admission } & \multirow{3}{*}{ t-test p } & \multicolumn{2}{|c|}{ After 1 month } & \multirow{3}{*}{ t-test p } & \multicolumn{2}{|c|}{ After 2 month } & \multirow{3}{*}{ t-test p } \\
\hline & study & Control & & study & Control & & study & Control & \\
\hline & $\overline{\boldsymbol{X}} \pm$ SD & $\bar{X} \pm$ SD & & $\overline{\boldsymbol{X}} \pm$ SD & $\bar{X} \pm$ SD & & $\overline{\boldsymbol{X}} \pm$ SD & $\overline{\boldsymbol{X}} \pm \mathbf{S D}$ & \\
\hline Anxiety & $76.3 \pm 7.83$ & $76.8 \pm 11.0$ & $\begin{array}{l}0.31 \\
0.75(\mathrm{NS})\end{array}$ & $26.4 \pm 12.3$ & $77.9 \pm 8.92$ & $\begin{array}{l}51.5 \\
0.001 \text { (HS) }\end{array}$ & $27.6 \pm 13.4$ & $77.9 \pm 8.92$ & $\begin{array}{l}50.3 \\
0.001 \text { (HS) }\end{array}$ \\
\hline Fatigue & $14.5 \pm 14.9$ & $12.7 \pm 13.5$ & $\begin{array}{l}0.83 * \\
0.40 \text { (NS) }\end{array}$ & $35.8 \pm 6.78$ & $14.5 \pm 12.4$ & $\begin{array}{l}21.3 \\
0.001 \text { (HS) }\end{array}$ & $35.4 \pm 4.56$ & $14.3 \pm 12.3$ & $\begin{array}{l}13.4 \\
0.001 \text { (HS) }\end{array}$ \\
\hline Dysnea & $19.7 \pm 1.80$ & $19.6 \pm 1.69$ & $\begin{array}{l}0.34 \\
0.73(\mathrm{NS})\end{array}$ & $6.65 \pm 3.17$ & $20.4 \pm 3.39$ & $\begin{array}{l}13.7 \\
0.001 \text { (HS) }\end{array}$ & $7.21 \pm 1.05$ & $20.4 \pm 3.39$ & $\begin{array}{l}31.1 \\
0.001 \text { (HS) }\end{array}$ \\
\hline
\end{tabular}

*Mann-Whitney test NS: non-significant HS: highly-significant 
This table shows the mean anxiety, fatigue and dyspnea among studied groups. There were highly statistical significant differences between study and control group regarding anxiety, fatigue and dyspnea after one and two months of teaching ( $\mathrm{P}$ $<0.001)$.

Table 4. Distribution of patients of both studied groups according to mean vital signs at three different intervals: on admission, one and two months post teaching.

\begin{tabular}{|c|c|c|c|c|c|}
\hline \multirow{3}{*}{ Vital sign } & \multicolumn{3}{|l|}{ Study group $(\mathrm{N}=70)$} & \multirow{3}{*}{ Paired t-test } & \multirow{3}{*}{$P$ value } \\
\hline & On admission & After 1month & After 2month & & \\
\hline & $\bar{X} \pm$ SD & $\bar{X} \pm$ SD & $\bar{X} \pm$ SD & & \\
\hline Temperature & $37.4 \pm 2.11$ & $37.2 \pm 1.23$ & $37.1 \pm 0.11$ & $\begin{array}{l}0.69 \\
1.19\end{array}$ & $\begin{array}{l}\mathrm{P} 1: 0.494 \text { (NS) } \\
\mathrm{P} 1: 0.236 \text { (NS) }\end{array}$ \\
\hline Pulse rate & $83.2 \pm 7.89$ & $79.9 \pm 8.95$ & $77.7 \pm 9.69$ & $\begin{array}{l}2.96 \\
3.40\end{array}$ & $\begin{array}{l}\mathrm{P} 1: 0.004 \text { (S) } \\
\mathrm{P} 2: 0.001 \text { (HS) }\end{array}$ \\
\hline Respiratory rate & $27.2 \pm 3.01$ & $19.8 \pm 1.35$ & $18.1 \pm 0.95$ & $\begin{array}{l}23.7 \\
23.4\end{array}$ & $\begin{array}{l}\mathrm{P} 1: 0.001 \text { (HS) } \\
\mathrm{P} 2: 0.001 \text { (HS) }\end{array}$ \\
\hline \multicolumn{6}{|l|}{ Blood pressure } \\
\hline Systole & $136.3 \pm 36.7$ & $120.1 \pm 10.9$ & $120.3 \pm 10.2$ & $\begin{array}{l}5.43 \\
3.87\end{array}$ & $\begin{array}{l}\mathrm{P} 1: 0.001 \text { (HS) } \\
\mathrm{P} 2: 0.001 \text { (HS) }\end{array}$ \\
\hline Diastole & $91.5 \pm 9.42$ & $78.6 \pm 11.5$ & $82.1 \pm 10.7$ & $\begin{array}{l}6.86 \\
5.93\end{array}$ & $\begin{array}{l}\mathrm{P} 1: 0.001 \text { (HS) } \\
\mathrm{P} 2: 0.001 \text { (HS) }\end{array}$ \\
\hline Vital sign & Control group $(\mathrm{N}=70)$ & & & & \\
\hline Temperature & $37.3 \pm 2.12$ & $37.1 \pm 1.42$ & $37.1 \pm 1.12$ & $\begin{array}{l}0.20 \\
0.70\end{array}$ & $\begin{array}{l}\mathrm{P} 1: 0.513 \text { (NS) } \\
\mathrm{P} 2: 0.486 \text { (NS) }\end{array}$ \\
\hline Pulse rate & $84.3 \pm 3.92$ & $84.9 \pm 5.81$ & $85.1 \pm 0.001$ & $\begin{array}{l}0.72 \\
1.71\end{array}$ & $\begin{array}{l}\mathrm{P} 1: 0.475 \text { (NS) } \\
\mathrm{P} 2: 0.081 \text { (NS) }\end{array}$ \\
\hline Respiratory rate & $26.7 \pm 1.72$ & $26.4 \pm 1.02$ & $26.4 \pm 1.02$ & $\begin{array}{l}1.26 \\
1.26\end{array}$ & $\begin{array}{l}\mathrm{P} 1: 0.211 \text { (NS) } \\
\mathrm{P} 2: 0.211 \text { (NS) }\end{array}$ \\
\hline \multicolumn{6}{|l|}{ Blood pressure } \\
\hline Systole & $130.1 \pm 10.8$ & $132.2 \pm 10.5$ & $133.1 \pm 10.2$ & $\begin{array}{l}1.17 \\
1.69\end{array}$ & $\begin{array}{l}\mathrm{P} 1: 0.245 \text { (NS) } \\
\mathrm{P} 2: 0.093 \text { (NS) }\end{array}$ \\
\hline Diastole & $92.1 \pm 7.20$ & $93.1 \pm 7.21$ & $93.5 \pm 0.001$ & $\begin{array}{l}0.82 \\
1.63\end{array}$ & $\begin{array}{l}\mathrm{P} 1: 0.4 .13 \text { (NS) } \\
\mathrm{P} 2: 0.106 \text { (NS) }\end{array}$ \\
\hline
\end{tabular}

P1: between on admission and after 1 month P2: between on admission and after 2 months NS: non-significant S: significant HS: highly-significant

This table shows mean vital signs among both studied group. There was no statistical significant difference in the control group regarding temperature, pulse and respiratory rate and systolic and diastolic blood pressure between on admission and one month and on admission and two month.
While there was highly statistical significant difference among study group regarding pulse and respiratory rate and systolic and diastolic blood pressure between on admission and one month and on admission and two months of teaching $(\mathrm{P}<0.001)$.

Table 5. Distribution of mean vital sign among both studied groups at three different intervals: on admission, one and two months post teaching.

\begin{tabular}{|c|c|c|c|c|c|c|c|c|c|}
\hline \multirow{3}{*}{ Vital sign } & \multicolumn{8}{|c|}{ Studied group } & \multirow{3}{*}{ t-test $p$ value } \\
\hline & \multicolumn{2}{|c|}{ On admission } & \multirow{2}{*}{$\begin{array}{l}\text { t-test } p \\
\text { value }\end{array}$} & \multicolumn{2}{|c|}{ After 1 month } & \multirow[b]{2}{*}{ t-test $p$ value } & \multicolumn{2}{|c|}{ After 2 month } & \\
\hline & $\begin{array}{l}\text { study } \\
\bar{X} \pm \text { SD }\end{array}$ & $\begin{array}{l}\text { Control } \\
\bar{X} \pm \text { SD } \\
\end{array}$ & & $\begin{array}{l}\text { Study } \\
\bar{X} \pm \text { SD }\end{array}$ & $\begin{array}{l}\text { Control } \\
\bar{X}_{ \pm \text {SD }} \\
\end{array}$ & & $\begin{array}{l}\text { study } \\
\bar{X} \pm \text { SD }\end{array}$ & $\begin{array}{l}\text { Control } \\
\bar{X} \pm \text { SD } \\
\end{array}$ & \\
\hline Temperature & $37.4 \pm 2.11$ & $37.3 \pm 2.12$ & $\begin{array}{l}0.28 \\
0.77 \text { (NS) }\end{array}$ & $37.2 \pm 1.23$ & $37.1 \pm 1.42$ & $\begin{array}{l}0.45 \\
0.65 \text { (NS) }\end{array}$ & $37.0 \pm 0.001$ & $37.1 \pm 1.12$ & $\begin{array}{l}0.10 \\
0.45 \text { (NS) }\end{array}$ \\
\hline Pulse rate & $84.3 \pm 7.11$ & $84.3 \pm 3.92$ & $\begin{array}{l}0.01 \\
1.0(\mathrm{NS})\end{array}$ & $79.9 \pm 7.01$ & $84.9 \pm 5.81$ & $\begin{array}{l}4.59 \\
0.001(\mathrm{HS})\end{array}$ & $77.7 \pm 9.69$ & $85.1 \pm 0.001$ & $\begin{array}{l}9.25 \\
0.001(\mathrm{HS})\end{array}$ \\
\hline $\begin{array}{l}\text { Respiratory } \\
\text { rate }\end{array}$ & $27.2 \pm 3.01$ & $26.7 \pm 1.72$ & $\begin{array}{l}0.50 \\
1.21(\mathrm{NS})\end{array}$ & $19.8 \pm 1.35$ & $26.4 \pm 1.02$ & $\begin{array}{l}32.6 \\
0.001 \text { (HS) }\end{array}$ & $18.1 \pm 0.95$ & $26.4 \pm 1.02$ & $\begin{array}{l}49.8 \\
0.001(\mathrm{HS})\end{array}$ \\
\hline \multicolumn{10}{|l|}{ Blood pressure } \\
\hline Systole & $136.3 \pm 36.7$ & $130.1 \pm 10.8$ & $\begin{array}{l}1.36 \\
0.17(\mathrm{NS})\end{array}$ & $120.1 \pm 10.9$ & $132.2 \pm 10.5$ & $\begin{array}{l}12.1 \\
0.001 \text { (HS) }\end{array}$ & $120.3 \pm 10.2$ & $133.1 \pm 10.2$ & $\begin{array}{l}7.20 \\
0.001 \text { (HS) }\end{array}$ \\
\hline Diastole & $91.5 \pm 9.42$ & $92.1 \pm 7.20$ & $\begin{array}{l}0.42 \\
0.67 \text { (NS) }\end{array}$ & $78.6 \pm 11.5$ & $93.1 \pm 7.21$ & $\begin{array}{l}14.5 \\
0.001(\mathrm{HS})\end{array}$ & $82.1 \pm 10.7$ & $93.5 \pm 0.001$ & $\begin{array}{l}8.91 \\
0.001 \text { (HS) }\end{array}$ \\
\hline
\end{tabular}

NS: non-significant HS: highly-significant

This table shows mean vital signs among study and control group. Regarding temperature there was no statistical significant difference among study and control group on admission, one and two months post teaching. Regarding pulse, respiratory rate and systolic and diastolic blood pressure there was a highly statistical significant difference between study and control group one month as well as two months post teaching $(\mathrm{P}<0.001)$. 
Table 6. Distribution of patients of both studied groups in relation to cough at three different intervals: on admission, one and two months post teaching.

\begin{tabular}{|c|c|c|c|c|c|c|c|c|c|}
\hline \multirow{3}{*}{ Studied variable } & \multicolumn{8}{|l|}{ Studied group } & \multirow{3}{*}{$\chi^{2} \mathbf{p}$ value } \\
\hline & \multicolumn{2}{|l|}{ On admission } & \multirow[b]{2}{*}{$\chi^{2}$ p value } & \multicolumn{2}{|c|}{ After 1month } & \multirow[b]{2}{*}{$\chi^{2} \mathrm{p}$ value } & \multicolumn{2}{|c|}{ After 2 month } & \\
\hline & Study (No)\% & $\begin{array}{l}\begin{array}{l}\text { Control } \\
\text { (No)\% }\end{array} \\
\end{array}$ & & $\begin{array}{l}\text { study } \\
\text { (No)\% }\end{array}$ & $\begin{array}{l}\begin{array}{l}\text { Control } \\
\text { (No)\% }\end{array} \\
\end{array}$ & & $\begin{array}{l}\text { study } \\
\text { (No)\% }\end{array}$ & \begin{tabular}{l|}
$\begin{array}{l}\text { Control } \\
\text { (No)\% }\end{array}$ \\
\end{tabular} & \\
\hline \multicolumn{10}{|l|}{ Cough } \\
\hline Present & $63(90)$ & $65(92.9)$ & 0.36 & $9(12.9)$ & $62(88.6)$ & 80.3 & $8(11.4)$ & $60(85.7)$ & 77.3 \\
\hline Absent & $7(10)$ & $5(7.1)$ & $0.54(\mathrm{NS})$ & $61(87.1)$ & $8(11.4)$ & 0.001 (HS) & $62(88.6)$ & $10(14.3)$ & $0.001(\mathrm{HS})$ \\
\hline \multicolumn{10}{|l|}{ Cough } \\
\hline Productive & $56(88.9)$ & $50(76.9)$ & 3.22 & $4(44.4)$ & $48(77.4)$ & 4.36 & $3(37.5)$ & $47(78.3)$ & 6.05 \\
\hline Non productive & $7(11.1)$ & $15(23.1)$ & 0.07 (NS) & $5(55.6)$ & $14(22.6)$ & $0.03(\mathrm{~S})$ & $5(62.5)$ & $13(21.7)$ & $0.01(\mathrm{~S})$ \\
\hline
\end{tabular}

NS: non-significant S: significant HS: highly-significant

Presence of cough was illustrated in $90 \%$ and $92.9 \%$ in study and control group respectively. While post one month cough was absent in $87.1 \%$ of study group while present in $88.6 \%$ of control group. As well as post two months of teaching cough was absent in $88.6 \%$ of study group while present in $85.7 \%$ of control group. There was a highly statistical significant difference between study and control group one and two months post teaching $(\mathrm{P}<0.001)$. Regarding productivity of cough, there was statistical significant difference between study and control group one and two months post teaching.

Table 7. Correlation between anxiety, fatigue and dyspnea among study group one month post teaching.

\begin{tabular}{lll}
\hline \multirow{2}{*}{ Studied variable } & Anxiety & \\
\cline { 2 - 3 } & R & P value \\
\hline Fatigue & 0.286 & $0.025(\mathrm{~S})$ \\
Dyspnea & 0.330 & $0.005(\mathrm{~S})$ \\
\hline
\end{tabular}

S: significant

This table shows the correlation between anxiety, fatigue and dyspnea among study group after one month of teaching. There was a positive correlation between anxiety, fatigue and dyspnea among study group one month post teaching. As the anxiety increases the fatigue and dyspnea symptoms increase and vice versa.

\section{Discussion}

Chronic obstructive pulmonary disease (COPD) is an obstructive and progressive airway disease associated with a reduction in daily physical activity and psychological problems that contribute to the patient's disability and poor health-related quality of life (HRQoL). Indeed the main benefits of comprehensive PR programs for patients with COPD include a decrease in symptoms (dyspnea and fatigue) improvements in exercise tolerance, reduction of health care utilization particularly bed days, as well as an increase in physical activity [36].

Regarding characteristics of the patients under study, it was found that the mean age for the study and control group was $51.8 \pm 12.8$ and $52.2 \pm 12.6$ years respectively. This finding is going with the studies of Salah, et al., (2013) [37] report that more than half of the study sample had mean age 55 and standard deviation \pm 5.7 . This finding is inconsistent with Tel, et al., (2012) [38] who found out that mean age of the COPD patients in their study was 66.03 years $(\mathrm{SD}=11.33)$. About two thirds of the studied sample was male; this finding is consistent with the studies of Salah, et al., (2013) [37] report that most of the study sample was male. Also the present study was consistent with Mohamed (2005) [39] who found that, the entire study sample was male.

The present study found that about two thirds of the studied samples were smoker before the teaching. This result is in the same line with National Heart, Lung, and Blood Institute (2013) [40], report that COPD most often occurs in people with a history of smoking either current or former smokers. Also, as many as one out of six people with COPD never smoked. While post intervention one fifth of studied group were smoking. This may be attributed to instruction given to the patient about the risk of smoking by the researcher. Also the finding of the study was supported by Velloso and Jardim (2006) [41] report that, the patient with COPD should share in developing a management plan, including: Stopping smoking and preventing a relapse, knowing the medication needed, using the inhalation devices and preventing and managing a flare up, exercise and physical activity, breathlessness, breathing control and energy conservation, airway clearance: keeping lungs clear, home oxygen therapy and managing stress, anxiety and depression.

As regard to the clinical parameter it was noticed that post teaching the patients of study group had an improvement of clinical parameter as evident by improvement of respiratory and heart rate and blood pressure compared to patient of their control who follow the routine hospital care only. This may be due to improvement of knowledge and the instruction given about relaxation and breathing exercises. The finding of the study group was in line with Garcia-Aymerich (2006) [29] they stated that, scheduling time to relax daily is important. Relaxation can be formal, such as guided relaxation practice, or informal, such as watching football or listening to music. Formal relaxation practice helps to increase the metabolism, slow the heartbeat, relax the muscles, slow the breathing and lower the blood pressure

According to the current study findings, the majority of the study group did not had cough and about two thirds of 
the patient who had cough had nonproductive cough as compared to their control group who follow the routine hospital care only. This may be due to improvement of knowledge and following the instruction given about bronchial hygiene and smoking cessation. This result goes on in the same line with Kanner et al., (1999) [42] in this prospective randomized trial using an intention to treat analysis, smokers with early COPD who were assigned to a smoking-cessation intervention had fewer respiratory symptoms as chronic cough, chronic phlegm production, wheezing and shortness of breath after 5 years of follow-up. Sustained quitters had the lowest prevalence of all four symptoms, whereas continuous smokers had the greatest prevalence of these symptoms. Also Peter and Calverley (2013) [28] stated that smoking cessation early in the natural history of the disease remains the most effective way of reducing cough but other therapies show some promise.

Regarding dyspnea the present study revealed highly statistical significant differences between patients of the study and control groups. This may be due to improvement of knowledge and following the instruction given about relaxation and breathing exercises. This finding goes in the same line with Hai-qin et al., (2009) [27] who found that pulmonary rehabilitation has positive effects on the quality of life among patients with COPD. Respiratory exercises are a part of the pulmonary rehabilitation program aiming at improvement and control of the disease symptoms, especially dyspnea, [43]. Bavarsad et al., (2015) [44] stated that there was no difference in dyspnea between the two groups before training; following the training period, there was statistically significant decrease in dyspnea in the study group. There was also a significant difference between the two groups at the end of the study $(P=0.0001)$. Moreover other studies by Reardon, et al., (2015) [45] Von Leupoldt, et al., (2008) [46] also was consistent with the result of the present study as they found that intensive 3-week outpatient pulmonary rehabilitation is associated with improvements in exercise capacity, dyspnea, and HRQL in male and female patients irrespective of COPD severity.

Fatigue may be affected by dyspnea and is frequently mentioned by the patients [10]. Results of the present study showed a reduction in the fatigue intensity among COPD patients undergoing teaching. This may be attributed to the fact that the researchers ensured that the patient following the instruction given about breathing exercise and relaxation technique during follow up and by telephone. This results are in line with Zakerimoghadam, et al., (2011) [47] report that a desirable effects of respiratory exercises on the reduction of fatigue intensity in COPD patients, it helps those nurses who are in closer contact with the patients to take an effective step for reduction of fatigue, improvement of symptoms, and as a result, upgrading of the level of health and quality of life among such patients, through introducing this low cost, inoffensive, and non medical procedure and encouraging its application. Also Ige, et al., (2010) [48] found that there was still a significant decline in the mean fatigue score from 2.7 at three months to 1.6 at six months $(\mathrm{p}<0.05)$. In addition, at six months a significant improvement compared to baseline was maintained. This was similar to what was reported by Mc Carthy, et al., (2015) [49] who found that Pulmonary rehabilitation relieves dyspnea and fatigue, improves emotional function and enhances the sense of control that individuals have over their condition. These improvements are moderately large and clinically significant. Rehabilitation serves as an important component of the management of COPD and is beneficial in improving health-related quality of life and exercise capacity

Current study also found significant improvement in anxiety symptoms in patients of the study group, compared to their control. Results was in line with the previous studies as Kayahan (2006) [50] who found significant decrease in the anxiety symptoms in the rehabilitation group at the end of the program and also this decrease was statistically significant compared to the control group. The current results support previous studies by Ninot, et al., (2003) [51] and Garuti, et al., (2013) [52] they emphasize that psychological improvement follows rehabilitation in patients with COPD. Coventry (2009) [53] show that comprehensive pulmonary rehabilitation, which includes exercise training and disease education or psychosocial support or both, can effectively improve anxiety and depression in COPD. Da Costa, et al., (2014) [54] stated that Pulmonary Rehabilitation Program improves levels of depression and anxiety as well as the quality of life in patients with COPD. Ige, et al., (2010) [48] stated that before the course, 17 patients $(40 \%)$ had a significant level of anxiety, according to the recommended cut-off score equal to or greater than eight. On completion of the programme the number above the cut-off level had fallen to $11(27 \%)$.

Moreover current results is due to providing emotional support to the patient through continuing social interaction with the researcher; by encouraging the patient to experience mastery over his chronic disease, and optimism about controlling it, through education and through the learning of specific techniques for dealing with it e.g. relaxation technique, systematic bronchial hygiene and breathing retraining; and on the assumption that these techniques are effective, by enhancing the patients' feeling of emotional well-being as a response to his improved physical well-being.

It was concluded that there was a positive correlation between dyspnea, fatigue and anxiety and as dyspnea scores increased so did mean fatigue and anxiety scores. This result is consistent with previous studies that have noted significant relationships between dyspnea and fatigue [55-58]. Also Kapella et al., (2006) [59] reported that there was significant correlation between dyspnea and fatigue scores among the COPD patients.

\section{Conclusion}

The current study concluded that dyspnea, fatigue, cough, vital signs and anxiety had been improved in patients with 
COPD who received the teaching compared to their control.

\section{Recommendations}

Based on the findings of the present study the following recommendations are derived and suggested:

1. Initiate hospital-based pulmonary rehabilitation teaching program.

2. A booklet should be available and distributed for all patients with COPD about anatomy, pathophysiology, disease education, breathing techniques and pharmacology, oxygen therapy, smoking cessation, inhalation techniques, symptom management, psychological interventions, anxiety management and relaxation.

\section{References}

[1] Global Strategy for the Diagnosis, Management and Prevention of COPD, Global Initiative for Chronic Obstructive Lung Disease (GOLD) 2008. Available from: http://www.goldcopd.org.

[2] World Health Organization. (2008) chronic obstructive pulmonary disease (COPD). Available from http:// www.who.int/mediacentre/factsheets/fs315/en/index.html

[3] World Health Organization (WHO) (2013): Chronic obstructive pulmonary disease (COPD), Fact sheet No. 315, Reviewed October 2013.

[4] Tageldin MA, Nafti S, Khan JA, Nejjari C, Beji M, Mahboub B, Obeidat NM, Uzaslan E, Sayiner A, Wali S, Rashid N, El Hasnaoui A. (2012): Distribution of COPD-related symptoms in the Middle East and North Africa: results of the BREATHE study. Respir Med. 2012; 106 Suppl 2: S25-32.

[5] Khattab, A., Javaid, A., Iraqi, G., Alzaabi, A., Kheder, A., Koniski, M., Shahrour, N., Taright, S., Idrees, M., Polatli, M., Rashid, N., \& El Hasnaoui, A. Smoking habits in the Middle East and North Africa. (2012). Respiratory Medicine, 106 (2): 16-24.

[6] Idrees, M., Koniski, M., Taright, S., Shahrour, N., Polatli, M., Ben Kheder, A., Alzaabi, A., Iraqi, G., Khattab, A., Javed, A., Rashid, N., El Hasnaoui, A. (2012). Management of chronic obstructive pulmonary disease in the Middle East and North Africa. Respir Med. 106 Suppl 2: S33-44.

[7] American Lung Association. (2007). Alpha-1 related emphysema. Available at: www.lungusa.org

[8] Maek PM, Lareau SC. (203) Critical outcomes in pulmonary rehabilitation: assessment and evaluation of dyspnea and fatigue. J Rehabil Res Dev; 40 (5 Suppl 2): 13-24.

[9] Theander K. (2004) Fatigue in patients with chronic obstructive pulmonary disease. J Advanced Nursing; 45 (2): 172-7.

[10] Wong KJ, Goodridge D, Marciniuk DD, Rennie D. (2010) Fatigue in patients with COPD participating in a pulmonary rehabilitation program. Int J Chronic Obstr Pulmo Dis. 2010; 5: 319-26.

[11] Agnieszka Lewko A, Bidgood PL, Garrod R. (2009)
Evaluation of psychological and physiological predictors of fatigue in patients with COPD. BMC Pulmo Med; 9 (47).

[12] Kasper DL. (2003) Harrison's principals of internal medicine. New York: Mc Graw-Hill Co.

[13] Ramadan, E., Ibrahim, I, Ramadan, S., and Ayman, A (2011). Prevalence of anxiety and depression among the Egyptian chronic obstructive pulmonary disease patients. Egy. J. Psychiatry, Oct, 321 (3); 19-26.

[14] Segan, L, perra R, Bullen C (2011). Helping smokers with depression to quit smoking. Med. J. Aust. 195: 5 7-11.

[15] Jain, A and Lolak, S (2009). Psychiatric aspects of chronic lung disease. Current psychiatry reports, 11: 219-25.

[16] Cleland, J., Lee, A., and Hall, S., (2007). Association of depression and anxiety with gender, age, health-related quality of life and symptoms in primary COPD patients. Family Practice: $24: 217-23$.

[17] Omachi, T. Kats, P., yelin E. (2009). Depression and health related quality of life in chronic obstructive pulmonary disease. Am. J Med., 122 (778) 9-15.

[18] Emery, C, Green M, and Such (2008). Neuropsychiatric function in chronic lung disease: - the role of pulmonary rehabilitation. Resp. care, 53 (9): 1208-1216.

[19] Jones, P., Brusselle G, Negro, R, Ferrer M, Kardos P, Levy M, Perez T, Adamek L, and Ban, K N. (2011). Health related quality of life in patients with COPD severity within primary care in Europe. Respir Med., 105: 57-6.

[20] Zahng, M, Cheung M, and Mak E. (2011): Prevalence of depressive symptoms in patients with chronic obst. Dis: a systematic review Gen. hosp. psychiatry, 33: 217-23.

[21] Ferrerra, T., Beachamp, M., Robles, P., Goldstein, R., and Broks, D, (2014). Measurement of activities of daily living in patients with COPD. Chest; 145 (2): 253-71.

[22] Arnolda E, Brutonb A, Ellis-Hillb C (2006) Adherence to pulmonary rehabilitation: A qualitative study. Respiratory Med.; 100 (10): 1716-23.

[23] Ries AL, Bauldoff GS, Carlin BW, Casaburi R, Emery CF, Mahler DA, et al. (2007) Pulmonary rehabilitation: Joint ACCP/ ACVPR evidence-based clinical practice guidelines. Chest; 131 (5 suppl): 4S-42S.

[24] Güell R, Resqueti V, Sangenis M, Morante F, Martorell B, Casan P,.(2006) Impact of pulmonary rehabilitation on psychosocial morbidity in patients with severe COPD. Chest.; 129: 899-904.

[25] Kozora, E., Tran, Z. V., and Make, B. (2002) Neurobehavioral improvement after brief rehabilitation in patients with chronic obstructive pulmonary disease. J Cardiopulm Rehabil. 22: 426-430.

[26] Gosselink R. (2004) Breathing techniques in patients with chronic obstructive pulmonary disease (COPD). Chron Respiratory Dis; 1: 163-72.

[27] Hai-qin, XU, Wen-ji C, Li-wen Q, Li Y, And Qing H. (2009) Effects of respiration rehabilitation nursing on living quality of life elderly patient with chronic obstructive pulmonary disease. Nursing J Chinese People's Liberation Army.; 12. 
[28] Peter MA, Calverley (2013). Cough in chronic obstructive pulmonary disease: is it important and what are the effects of treatment? Calverley; licensee Bio Med Central Ltd.

[29] Garcia-Aymerich J, Lange P, Benet M, Schnohr P, Antó J. (2006) Regular physical activity reduces hospital admission and mortality in chronic obstructive pulmonary disease: a population based cohort study. Thorax. 61: 772-8.

[30] Kinsman R. A., Fernandez E., Schocket M., Dirks J. F. \& Covino N. A. (1983) Multidimensional analysis of the symptoms of chronic bronchitis and emphysema. Journal of Behavioral Medicine 6, 339-57.

[31] Webster, K., Cella, D., \& Yost, K. (2003). The functional assessment of chronic illness therapy (FACIT) measurement system: properties, applications and interpretation. Health and Quality of Life Outcomes, 1 (79), 1-7.

[32] Chandran, V., Bhella, S., Schentag, C., \& Gladman, D. (2007). Functional assessment of chronic illness therapy-fatigue scale is valid in patients with psoriatic arthritis. Annals of the Rheumatic Diseases, 66(7), 936-39.

[33] Spielberger, C., D., Gorsuch, R. L., Lushene, R., Vagg, P. R. \& Gacobs, G. A. (1983). Manual for the state- trait anxiety inventory. Available at www.apa.org. retervied on 20-2-2012.

[34] Abd Elkhalek A. (2008). reliability, factorial validity, and means on the kuwait university anxiety scale: a UK university sample. Psychological Reports; 102 (3): 867.

[35] Dawson B., and Trapp R., (2001): Reading the medical literature: Basic \& Clinical Biostatistics. 3rd ed., New York. Lange Medical Book/ McGraw - Hill. Medical Publication Division, 7-9, 161-218, 305-14.

[36] CorhayJ, Dang DN, Cauwenberge HV, and Louis R (2014) Pulmonary rehabilitation and COPD: providing patients a good environment for optimizing therapy Int J Chron Obstruct Pulmon; 9: 27- 39.

[37] Salah M, Hamdi A, Shehata H (2013) Improving breathlessness and fatigue in patient with COPD. Journal of American Science; 9(12), 470-482.

[38] Tel, H., Bilgiç, Z., \& Zorlu, Z. (2012). Evaluation of Dyspnea and Fatigue Among the COPD Patients, Chronic Obstructive Pulmonary Disease - Current Concepts and Practice. Available at: http://www.intechopen.com/

books/chronicobstructivepulmonary-disease- currentconcepts-and practice/evaluation-of-dyspnea-and-fatigueamongthe-copd patients

[39] Mohamed, A. (2005). Pulmonary Rehabilitation: Selfcare Strategies for Chronic Obstructive Pulmonary Disease Patients, unpublished doctorate dissertation in nursing science, Faculty of Nursing, Ain Shams University.

[40] National Heart, Lung, and Blood Institute. (2013): COPD are you at risk? Available at www.nhlbi.nih.gov [last updated 2011 Sept; accessed 2013 Feb 11].

[41] Velloso, M., Jardim, J. (2006): Functionality of patients with chronic obstructive pulmonary disease: energy conservation techniques. Journal Brasilian Pneumol. 2006; 32 (6): 580-6.

[42] Kanner RE, Connett JE, Williams DE, Buist AS (1999): Effects of randomized assignment to a smoking cessation intervention and changes in smoking habits on respiratory symptoms in smokers with early chronic obstructive pulmonary disease: the Lung Health Study. Am J Med. 106 (4): $410-416$.

[43] Petty T L. (2006). The history of COPD. Int J Chron Obstruct Pulmon Dis.; 1 (1): 3-14.

[44] Bavarsad MB, Shariati A, Eidani E, and Latifi M (2015) The effect of home-based inspiratory muscle training on exercise capacity, exertional dyspnea and pulmonary function in COPD patients. Iran J Nurs.

[45] Reardon J; Awad E; Normandin E; Vale F; Clark B; and Zu Wallack RL (2015). The Effect of Comprehensive Outpatient Pulmonary Rehabilitation on Dyspnea. CHEST/105/4/APRIL 1047.

[46] Von Leupoldt A, Hahn E, Taube K, Schubert-Heukeshoven S, Magnussen H, Dahme B (2008) Effects of 3-week outpatient pulmonary rehabilitation on exercise capacity, dyspnea, and quality of life in COPD. Lung 186 (6): 387-91.

[47] Zakerimoghadam M, Tavasoli K, Nejad AK, Khoshkesht S. (2011) The Effect of Breathing Exercises on The Fatigue Levels of Patients with Chronic Obstructive Pulmonary Disease. Acta Med Indones-Indones J Intern Med. 43 (1) 293.

[48] Ige. O. M., Olarewaju R. K., Lasebikan V. O., and Adeniyi Y. O. (2010) Outpatient Pulmonary Rehabilitation in Severe Chronic Obstructive Pulmonary Disease. The Indian Journal of Chest Diseases \& Allied Sciences. 52, 197-201.

[49] McCarthy B, Casey D, Devane D, Murphy K, Murphy E, Lacasse Y. (2015) Pulmonary rehabilitation for chronic obstructive pulmonary disease. Cochrane Database of systematic reviews, Issue 2. Art. 03793.

[50] Kayahan B. (2006) Psychological outcomes of an outpatient pulmonary rehabilitation program in patients with chronic obstructive pulmonary disease. Respiratory Medicine; 100 (6): 1050-57.

[51] Ninot, G., Brun, A., Querias, G., Segi, A., Moullec, G., and Desplan, J. (2003) Psychosocial support for pulmonary rehabilitation in patients with chronic obstructive pulmonary disease. Rev Mal Respir.; 20: 549-57.

[52] Garuti, G., Cilione, C., Dell’Orso, D., Gorini, P., Lorenzi, M. C., Totaro, L. (2013) Impact of comprehensive pulmonary rehabilitation on anxiety and depression in hospitalized COPD patients. Monaldi Arch Chest Dis.; 59: 56-61.

[53] Coventry PA (2009) Does pulmonary rehabilitation reduce anxiety and depression in chronic obstructive pulmonary disease? Curr Opin Pulm Med.; 15(2): 143-9.

[54] Da Costa CC, de Azeredo Lermen C, Colombo C, Canterle DB, Machado ML, Kessler A, Teixeira PJ. (2014) Effect of a Pulmonary Rehabilitation Program on the levels of anxiety and depression and on the quality of life of patients with chronic obstructive pulmonary disease. Rev Port Pneumol.; 20 (6): 299-304.

[55] Baghai-Ravary, R., Quint, JK, Goldring, JJP, Hurst, JR., Donaldson, GC. \& Wedzicha, JA. (2009). Determinatnts and impact of fatigue in patients with chronic obstructive pulmonary disease. Respiratory Medicine, 103, 216-23. 
[56] Peters, JB., Heijdra, YF. Daudey, L., Boer, LM., Molema, J., Dekhuijzen, R., Schermer, TR. \& Vercoulen, JH. (2010). Course of normal and abnormal fatigue in patients with Chronic Obstructive Pulmonary Disease, and its relationship with domains of health status. Patient Education and Counselling, doi: 10.1016/j.pec.2010.08.021.

[57] Reichstein, JL. (2005). Relationship between symptoms and functional performance in COPD. Research in Nursing \& Health, 28, 39-47.
[58] Theander, K., Jakobsson, P., Jorgenson, N. \& Unosson, M. (2009). Effects of pulmonary rehabilitation on fatigue, functional status and health perceptions in patients with chronic obstructive pulmonary disease: A randomized controlled trial. Clinical Rehabilitation, 23, 125-136.

[59] Kapella, MC. Larson, JL., Patel, MK., Covey, MK. \& Berry, JK. (2006). Subjective fatigue, influencing variables, and consequences in Chronic Obstructive Pulmonary Disease. Nursing Research, 55, 10-17. 